cases in which the wife has conceived after her husband has been subjected to prostatectomy. If it were not for the fact that the wives of most men undergoing prostatectomy are themselves past child-bearing age, such cases would probably be more numerous. It must be remembered, however, that many surgeons divide the vasa in order to reduce the incidence of post-operative epididymitis, and that this leads to sterility.

It cannot be said that any one technique of prostatectomy is recognized as being superior to all others. What form of operation is carried out will depend on the state of the patient and on the surgeon's personal opinion. Retropubic prostatectomy and the Harris technique are both excellent operations for certain patients, but they should not be used as routine measures.

\section{Coronary Thrombosis and Air Travel}

Q.-Are there any objections to air travel for patients with a history of coronary thrombosis some years ago?

A.- Provided oxygen is used for flight above 10,000 feet $(3,000$ metres) there should be no greater risk to a subject well recovered from a coronary thrombosis in this mode of travel than in any other, and fatigue is likely to be considerably less.

\section{Thrombophlebitis Migrans}

Q.-What is the treatment for repeated attacks of thrombophlebitis over a period of 18 months involving the superficial veins of arms and legs in a woman of 48? The erythrocyte sedimentation rate is $11 \mathrm{~mm}$. in one hour, and the blood pressure $146 / 90 \mathrm{~mm} . \mathrm{Hg}$. She has no infected teeth or gall-bladder infection. Section of an infected vein has shown well-organized thrombus. Sulphonamides, large doses of vitamins, and the usual treatment for phlebitis have been unsuccessful. What further treatment could be tried, and what is the prognosis?

A.-This patient seems to be suffering from thrombophlebitis migrans, although the usual associated pyrexia and low blood pressure seem to be absent. Dicoumarol is very useful in this rebellious complaint, and should be administered so as to keep the prothrombin time double the normal and persisted in for three to six months. The condition is as a rule not disabling, and the patient should, if possible, be ambulatory; this can be attained by supporting the legs with elastic bandages. A long holiday in a warm place is often beneficial. The disease is not usually dangerous and burns itself out in time, but rarely it may progress to a malignant thrombophilia in which the largest vessels may become involved and even arteries be blocked, with consequent cardiac damage or loss of limbs.

\section{Quinine Test of Liver Function}

Q.-I have seen a reference to an article by Pallardo on the quinine test for liver function, for which he claimed good results. I should be grateful for details of procedure, the field of application, interpretation of results, and relative merits compared with other liver function tests.

A.- The quinine test for liver function was described by Pallardo in 1947 (Sem. méd., 54, 721), and depends on the detection of quinine in the urine after oral administration of the drug. Quinine sulphate 0.2 to $0.25 \mathrm{~g}$. is given to the fasting patient. The urine is collected at 30 minutes, two hours, and 12 hours afterwards. The three specimens of urine are tested for quinine with the Tanret reagent, which is prepared as follows. Dissolve $1.35 \mathrm{~g}$. of mercuric chloride in $25 \mathrm{ml}$. of water, add to this solution $3.32 \mathrm{~g}$. of potassium iodide dissolved in $25 \mathrm{ml}$. of water, then make the total solution up to $60 \mathrm{ml}$. with distilled water and add $20 \mathrm{ml}$. of glacial acetic acid to the mixture. After the Tanret reagent is added a positive reaction is indicated by the development of turbidity. Normal subjects give negative reactions under these conditions.

The test is positive in the urine from a high proportion of cases of liver damage, irrespective of the cause, although occasional negative findings are also recorded in conditions such as cirrhosis and infective hepatitis. The test may also be positive in cholecystitis and hepatic carcinomatosis, which would appear to limit its value in differential diagnosis. The author claims that it is a sensitive index of liver damage.

\section{NOTES AND COMMENTS}

Enlarged Liver after Amoebic Dysentery.-Dr. C. F. J. Cropper (Ronkswood, Worcester) writes: I should like to submit some comments on the answer to the query entitled "Enlarged Liver after Amoebic Dysentery" (“Any Questions?" August 20, p. 448). It appears to me that the writer was presented with a common, and in this case simple, problem to which he himself provided the solution by his demonstration of the regression of an enlarged liver beginning during the course of emetine injections. The history of amoebic dysentery and the response to this infallible therapeutic test can surely leave little doubt about the diagnosis. Incidentally, in general experience leucocytosis is frequently absent in amoebic hepatitis. There is no mention, either in the query or in the reply, of sigmoidoscopy. It is disturbing to find so essential a diagnostic procedure ignored in this way. If this neglect of sigmoidoscopy is widespread, innumerable cases of amoebiasis originating in both world wars are certainly being missed. (I use the word " both" advisedly, since more than one case has come to light in this hospital which has remained undiagnosed and untreated from the 1914-18 war: these have been diagnosed purely on sigmoidoscopy appearances.) Whilst in no way belittling the significance of stool tests, it needs to be stressed that only the select few with long apprenticeship can identify cysts with competence, and in any case the chronic patient so often yields negative results. Hand in hand with microscopy should go sigmoidoscopy, the technique and interpretation of which can readily be taught. This strangely neglected instrument frequently gives in a few moments a certain answer in the search for amoebiasis Physicians handling cases potentially infected with this disease should have indelibly printed on their minds the picture of the tiny wart-like projections, aptly likened to colonies of pneumococci on blood-agar which are the commonest lesions of chronic amoebic dysentery (Lancet, 1945, 2, 460). In the tropical section of this hospital, in the first six months of this year no less than nineteen cases with negative stools but with dysenteric symptoms were revealed by the finding of these " pin-point craters." In the great majority of cases both symptoms and lesions cleared up with anti-amoebic treatment There is, in my opinion, no answer to the problem of amoebiasis in this and many other countries except the adoption of sigmoidoscopy as a simple out-patient procedure.

Wax in the Ears.--Mr. F. K. HAYMAN (Sharnbrook, Bedford) writes : Your correspondent ("Any Questions?" October 1, p. 767) asks about any prophylaxis against wax in the ears. I have found that a good deal of so-called wax is composed of bits of hair, dandruff, ordinary dust, etc., bound together by soap-shaving or toiletinsufficiently rinsed off, and probably pushed in by the towel. I have often found a soapy turbidity in the water used for syringing, and have cautioned such patients not to allow soap to enter the meatus if possible, and in any case to rinse about the ears very thoroughly.

Dichloracetylene Poisoning.-Dr. C. F. Scurr (London, S.W.) writes: Your answer upon this subject ("Any Questions ?" September 24, p. 717) is incomplete. Had the question been referred to an anaesthetist instead of an industrial toxicologist a more adequate answer would have been given. Dichloracetylene is a product of the decomposition of trichlore hylene with alkali under certain conditions-e.g., by soda lime in a closed-circuit anaesthetic apparatus. A detailed account of the toxic effects and necropsy findings is given by Humphrey and McClelland (British Medical Journal, 1944, 1.315) and by Carden (ibid., 1944, 1, 319).

\section{Correction}

Dr. Sidney G. Hamilton (Woolacombe, N. Devon) writes that in his letter on "Antihistamine Drugs in General Practice" ("Points from Letters," October 1, p. 760) the words " phenacetin and codeine compound" in the seventh line from the end of the paragraph should read "pyranisamine maleate."

All communications with regard to editorial business should be addressed to THE EDITOR, BRITISH MEDICAL JOURNAL, B.M.A. HOUSE, TAVISTOCK SQUARE, EDITOR, BRITISH MEDICAL JOURNAL, B.M.A. HoUSE, TAVISTOCK SQUARE,
LONDON, W.C.1. TELEPHONE: EUSTON 211. TELEGRAMS : Aitiology,
Westcent, London. Westcent, London. ORIGINAL ARTICLES AND LETTERS forwarded fo publication are understood to

unless the contrary be stated. uthors desiring REPRINTS should communicate with the Publishing Manager B.M.A. House. Tavistock Square, W.C.1, on receipt of proofs. Authors
overseas should indicate on MSS. if reprints are required, as proofs are not sent abroad.

ADVERTISEMENTS should be addressed to the Advertisement Manager. B.M.A. House, Tavistock Square, London, W.C.1 (hours 9 a.m. to 5 p.m.). TELEPHONE : EUSTON 2111. TELEGRAMS : Britmedads, Westcent, London. MEMBERS' SUBSCRIPTIONS should be sent to the SECRETARY of the Association.

B.M.A. SCotrish OFFICE : 7, Drumsheugh Gardens, Edinburgh. 